\title{
EL ABORTO TERAPÉUTICO EN NICARAGUA: EL DIÁLOGO COMO PARTE DE LA SOLUCIÓN AL CONFLICTO
}

\author{
Melba de la Cruz Barrantes Monge y Elizabeth Mercado Morales*
}

\begin{abstract}
Resumen: La derogación de la Ley del Aborto Terapéutico en Nicaragua ha generado un conflicto de opinión en la sociedad nicaragüense y, hasta el momento, no se ha llegado a un consenso en los distintos ámbitos de la sociedad. La Ley es clara en cuanto a prohibir esa práctica, pero es preciso hacer un adecuado análisis del tema, usando el diálogo como herramienta que contemple los principios bioéticos, para entender las implicancias positivas y negativas de la derogación de esta Ley en el binomio madre-hijo.
\end{abstract}

Palabras clave: aborto, bioética, ley, Nicaragua

\section{THERAPEUTIC ABORTION IN NICARAGUA: DIALOGUE AS A PART FOR THE CONFLICT'S SOLUTION}

Abstract: The withdrawal of the Law on Therapeutic Abortion in Nicaragua has generated a conflict of opinions in the Nicaraguan society and no consensus has been reached up to this minute in the different scopes of its community. The Law is clear as to forbid its practice, but it is essential to study an adequate subject's analysis: it is necessary to employ dialogue as a tool that would consider bioethics principles in order to understand both the positive and the negative implications of the derogation of this Law for the binomial mother-child.

Key words: abortion, bioethics, law, Nicaragua

\section{O ABORTO TERAPÊUTICO NA NICARÁGUA: O DIÁLOGO COMO PARTE DA SOLUÇÃO DO CONFLITO}

Resumo: A derrogação da Lei do Aborto Terapêutico na Nicarágua gerou um conflito de opinião na sociedade nicaragüense e até o presente momento, não se chegou a um consenso nos distintos segmentos da sociedade. A Lei é clara enquanto proíbe essa prática, porém é preciso fazer uma análise adequada do tema, usando o diálogo como ferramenta que contemple os princípios bioéticos, para entender as implicaçóes positivas e negativas da derrogação desta Lei no binômio mãe-filho.

Palavras chave: aborto, bioética, lei, Nicarágua

\footnotetext{
* Doctoras en Medicina y Cirugía, Especialistas en Medicina Interna. Ex alumnas del Programa de Formación en Ética de la Investigación Biomédica y Psicosocial, CIEB, Universidad de Chile, Nicaragua

Correspondencia: melcruzbar@hotmail.com
} 


\section{Introducción}

Desde el siglo IV antes de Cristo, Hipócrates, padre de la Medicina Moderna, estableció un juramento, conocido por todos los médicos: "No daré a nadie, aunque me lo pida, ningún fármaco letal, ni haré semejante sugerencia. Igualmente tampoco proporcionaré a mujer alguna un pesario abortivo"(1). Si bien este juramento es antiguo, mantiene su vigencia y debe seguir siendo el referente ético obligado de todos los médicos en su condición de justicia en su actuar como profesionales.

En aquel momento no se clasificaba el aborto en espontáneo o provocado. Tampoco existían formalmente los derechos de la mujer, del no nacido o del Estado como interventor del proceder del profesional de la salud, ya sea en relación con la atención de la mujer embarazada y como representante ante la ley del no nacido, como sucede ahora.

En el caso de Nicaragua, el aborto como tal no es considerado legal. Como una excepción, en 1891 el gobierno legalizó el aborto cuando existiese riesgo para la vida de la madre, dańos irreversibles al embrión o el feto, y cuando el embarazo fuese fruto de una violación o incesto. Para practicarlo se necesitaba el criterio unánime de al menos tres especialistas y el consentimiento de la madre o de un familiar de ésta. Sin embargo, esta ley fue anulada en 2006, por lo que el aborto terapéutico es penado por la ley a quienes se lo realicen y lo practiquen. Esto ha generado una controversia en cuanto a los derechos de las mujeres, de los no nacidos y de los médicos al practicar su profesión, percibiéndose una parcialización del tema a conveniencia de quien lo discuta.

Cual sea la opinión, debe estar fundamentada, argumentada y contar con toda la información para sostenerla, ya que el tema del aborto terapéutico puede ser tratado desde diferentes aspectos (bioético, religioso, social, por ejemplo). En este escrito se analizará desde el punto de vista bioético, considerando el diálogo como la mejor herramienta para esta controversia.

El embarazo es una condición normal y, en la mayoría de las situaciones, no debe abordarse como un problema o enfermedad. Sin embargo, no se puede negar que este período implica cambios hormonales en el organismo que pueden complicar la salud del producto y de la madre. Por esta razón, en todos los países del mundo se han elaborado programas de salud para cuidar al binomio madre-hijo, ya que en ese momento la salud de la madre es susceptible de quebrantarse y el objetivo de estos programas es que el embarazo llegue a feliz término.

No debemos confundir una mujer con un embarazo no deseado, que busca abortarlo, con otra que lo está continuando por opción, porque quiere concebir y se está complicando su salud. En esta situación, se debe considerar la posibilidad de salvaguardar la vida de ambos. Con una adecuada información de las opciones terapéuticas, la mujer embarazada hará uso de su autonomía, el médico no hará daño, será justo y otorgará el mejor beneficio a estas dos personas.

\section{La mujer embarazada: derechos económicos y sociales}

En cuanto a los derechos de la familia, la Constitución nicaragüense señala en su Art. 74. "El Estado otorga protección especial al proceso de reproducción humana. La mujer tendrá protección especial durante el embarazo y gozará de licencia con remuneración salarial y prestaciones adecuadas de seguridad social"(2).

No caben dudas sobre los derechos de la mujer gestante cuando está inserta en el trabajo o cuando requiere asistencia médica. Sin embargo, en nuestra sociedad las mujeres embarazadas laboran en situaciones riesgosas que complican su salud y la del producto en formación. Muchas veces abortan de forma espontánea o llegan en un estado crítico de salud a los centros asistenciales en donde pueden perder su vida por falta de cuidados adecuados. Incluso, otras veces mueren en sus casas; ejemplo de esto son las mujeres que viven en las zonas rurales, en donde predomina la mayoría de muertes maternas nacionales.

Los principales factores causales de estas muertes maternas son los mismos que en el resto de los países pobres de nuestro continente: carencia de las condiciones mínimas de vida, que afecta más a personas vulnerables como lo es la mujer embarazada y su producto; desnutrición severa; pobre educación, que evita adecuados controles prenatales; aumento de la violencia hacia la mujer; creencias de una sexualidad dedicada a la reproducción; pobreza extrema secundaria a las condiciones del país y malas condiciones de trabajo y de ambiente. 
Dado que las causas de la mortalidad materna son multifactoriales, debemos preguntarnos si mantener la Ley 165 (del aborto terapéutico) daría respuesta a las siguientes interrogantes:

- ¿Se ha logrado reducir la muerte materna en países en vías de desarrollo por la aprobación del aborto terapéutico?

- ¿Será la mejor opción para evitar la mayoría de las muertes maternas en Nicaragua?

- ¿Es necesario reeducar a estas mujeres de alto riesgo y decirles que no tienen derecho a embarazarse para prevenir el riesgo de morir?

- Y si se embarazan, ¿deben practicarse el aborto terapéutico inmediatamente, como parte de una política pública, para que no mueran?

- ¿Quién garantizará que esta madre no vuelva a embarazarse y a reexponer su vida?

- ¿Son adecuados los controles prenatales?

- ¿Se ponen en práctica las consejerías?

- ¿Consentirán estas mujeres una esterilización después de este embarazo que pone en riesgo su vida?

- ¿Qué sucederá si ocurre una complicación producto del aborto?

Algunos aducen que derogar la ley del aborto terapéutico favorecería únicamente un incremento de abortos clandestinos(3) y, por ende, mayor riesgo en la salud de la mujer $(4,5)$.

Considerar que el aborto terapéutico es la solución es una salida fácil que no considera que, en Nicaragua, muchas de estas mujeres no tienen acceso a un centro asistencial o que, cuando llegan a éste, su condición de salud es tan grave que es difícil revertir su mortalidad. La responsabilidad es de toda la sociedad y del Estado para con la embarazada y su hijo (no solamente de la mujer, de su familia, del médico o del personal de salud). Lo más importante es darle el derecho de continuar su embarazo y mejorar sus condiciones de vida durante este período para no tener muertes que lamentar.

\section{Legislación nicaragüense con relación al aborto terapéutico (Ley $\mathrm{N}^{\circ}$ 603. Derogación del Artículo 165 del Código Penal)}

En el aborto terapéutico se trata de terminar con el embarazo y, con ello, con la vida del no nacido para preservar la vida de la madre. Se invocan aquí razones preventivas y curativas. Serían preventivas si se considerara que la gestación podría agravar o empeorar el pronóstico de una enfermedad de base; curativas cuando se considera que el embarazo está causando un peligro para la vida de la madre(6).

El Código Penal de Nicaragua regulaba la figura jurídica del aborto terapéutico en su Art. 165: "El aborto terapéutico será determinado científicamente, con la intervención de tres facultativos, por lo menos, y el consentimiento del cónyuge o pariente más cercano a la mujer, para los fines legales". El 26 de octubre fue aprobada por la Asamblea Nacional la Ley $\mathrm{N}^{\circ} 603$, "Ley de Derogación al Artículo 165 del Código Penal Vigente", la cual entró en vigencia el 17 de noviembre de 2006(7).

Posterior a la aprobación de la Ley $\mathrm{N}^{\circ} 603$, surgieron una serie de debates dentro de la sociedad nicaragüense. Asimismo, revistas extranjeras han denunciado situaciones ocurridas con posterioridad a la aprobación de esta Ley.

\section{Consecuencias positivas de la derogación del Artículo 165}

- Evita que personas inescrupulosas incrementen injustificadamente los abortos por embarazos no deseados, lo que se convertiría en una forma de controlar la natalidad en la sociedad nicaragüense, comportamiento no aceptado ni legal ni moralmente.

- El Estado de Nicaragua protege el derecho del no nacido, cumpliendo con el tratado firmado en el Pacto de San José, Artículo 4, Inciso 1, "El Derecho a la Vida: Toda persona tiene derecho a que se respete su vida. Este derecho estará protegido por la ley y, en general, a partir del momento de la concepción. Nadie puede ser privado de la vida arbitrariamente"(8). Del mismo modo, apoya lo expresado en la Constitución sobre los derechos individuales: "Art. 23. El derecho a la vida es inviolable e inherente a la persona humana. Art. 24. Toda persona tiene deberes para con la familia, la comunidad, la patria y la humanidad. Los derechos de cada persona están limitados por los derechos de los demás, por la seguridad de todos y por las justas exigencias del bien común. Corresponde al Estado generar políticas de salud pública encaminadas a disminuir las causas que provocan la muerte ma- 
terna y dotar a los centros de atención en salud de equipos y tecnología apropiada para lograrlo"(9).

- Genera una responsabilidad por parte de la mujer para acudir desde el momento en que crea estar embarazada y llevar sus respectivos controles prenatales en los centros de atención dispuestos para ello.

- Retoma la función del Ministerio de Salud en la década de los 80, que consistía en la detección de mujeres embarazadas y su reporte a los centros de salud para su captación al programa de controles prenatales. Esta conducta permitió detectar problemas a tiempo y evitar muertes maternas y fetales.

- Estimula las investigaciones desde un contexto bioético para definir, con resultados reales, los problemas en los que hay que incidir para evitar embarazos de alto riesgo y, si éstos se presentan, las condiciones para que el embarazo culmine de forma adecuada para la madre y su hijo.

- Salvaguarda la vida de una mujer embarazada, su producto y el bienestar de la familia, puesto que una muerte materna deja huérfanos a otros niños afectándose de este modo el núcleo familiar.

- Hace recaer la responsabilidad en todos los nicaragüenses, ya que la familia es la base de nuestra sociedad.

\section{Consecuencias negativas de la derogación del Artículo 165}

- Ningunas de las partes (a favor y en contra del aborto terapéutico) señala por qué defienden una u otra posición; o bien, cada uno de los grupos defienden sus intereses, aun dentro de los médicos nicaragüenses.

- No existe una política pública de salud, a corto plazo, dirigida a dotar de medios diagnósticos y terapéuticos a los centros de salud para evitar la muerte materna en zonas alejadas del país.

- Hay manipulación de la información, confundiendo a las personas involucradas que no entienden de leyes (médicos y embarazadas) y a la sociedad en general.

A la sociedad nicaragüense corresponde definir las decisiones para evitar la muerte del producto, de la madre o de ambos, de ser posible. Se trata de evitar el aborto terapéutico de forma indiscriminada. La extracción de un producto de la concepción vivo debe ser la última instancia, tras agotar todas las posibilidades médicas, como sería el caso puntual del embarazo tubárico.

\section{El papel del diálogo}

Los legisladores involucrados en la toma de decisiones no tienen intención de discutir más el problema. Cada una de las partes en conflicto debiera plantear sus posiciones con bases científicas y éticas.

Se debe promover la existencia de comités de bioética para la discusión y el diálogo sobre estas materias, en beneficio de madre e hijo y, por ende, familia y sociedad. Sobre todo estimular el estudio de casos porque, como todo en medicina, lo que aplica para un enfermo no aplica para otro. Esto último debe ir de la mano con programas y estrategias para abordar las causas y consecuencias de los embarazos de alto riesgo.

Lamentablemente, las leyes dependen de personas que no conocen el tema y, en algunas ocasiones, las decisiones son meramente políticas o comerciales. Así también, los tratamientos se deciden únicamente por el médico o un personal encargado de la atención, que interviene finalmente en el destino de la madre y el no nacido. Es necesario que, tanto los afectados como las autoridades y personal del centro asistencial, la Iglesia, el Estado y un representante de la comunidad (en el mejor de los casos una mujer que haya tenido una experiencia similar) participen de la decisión de salud.

La situación es más compleja cuando el médico debe tomar una decisión urgente para preservar la vida de la madre. En este caso, no hay tiempo de convocar un comité para la evaluación y decisión. Un médico con preparación ética considerará tanto la autonomía de la madre como los derechos del no nacido y, probablemente, así se adopte la decisión más acertada.

\section{Principios bioéticos que deben considerarse siempre}

Los principios bioéticos $(6,10)$ brindan algunas pautas para tomar esta clase de decisiones. En términos de la beneficencia no se debe olvidar que, en el caso de los abortos, existen dos pacientes sujetos de derechos (la madre y el hijo). Si pensamos en la autonomía, debemos considerar al derecho del sujeto a decidir sobre aquello que le afecta en su vida y su salud. La madre tiene derecho a participar en las decisiones terapéuticas que conciernen a ella y a su hijo, en forma subrogada. 
En el caso del no nacido, que no puede ejercer su autonomía, no significa que no la posea, porque hay derechos consagrados como los del Pacto de San José. Al considerar la justicia, el hijo y la madre tienen igual derecho a la vida y a recibir acciones que les permitan un desarrollo saludable. Por último, si queremos ser fieles a la no maleficencia, vale como máxima no realizar acciones perjudiciales, existiendo escasas excepciones que deben ser consensuadas por los implicados.

\section{Conclusión}

Las muertes maternas son causadas por una multiplicidad de factores, por lo tanto, el aborto terapéutico no es la única solución para disminuirlas. El embarazo es un acto de procreación y, en la medida de lo posible, debe preservarse la vida de la madre y del no nacido. Es muy importante tomar en cuenta que la salud de la mujer y de su hijo es responsabilidad de la familia, el Estado y la sociedad en general.

Debido a la diversidad de opiniones, las diferencias entre los casos y la responsabilidad del Estado y de toda la sociedad, se deben aprobar leyes que estimulen al diálogo para unificar criterios; además, promover la creación de comités de bioética en los que participen los afectados, las autoridades y el personal asistencial del centro, la Iglesia, el Estado y un representante de la comunidad. Dicho comité debe tomar en cuenta los principios bioéticos para tomar una decisión lo más correcta posible.

Cabe señalar que una "Ley de Comité de Bioética para el Aborto Terapéutico" debe ir de la mano con el desarrollo de programas y estrategias para abordar las causas y consecuencias de los embarazos de alto riesgo.

\section{Referencias}

1. Lama A. Historia de la Medicina: hechos y personajes. Santiago de Chile: Mediterráneo; 2004.

2. Base de Datos Políticos de las Américas. Constitución de Nicaragua de 1987 con Reformas de 1995; 2002. (Sitio en Internet) Disponible en: www.oas.org/juridico/MLA/sp/nic/sp_nic-int-text-const.pdf Último Acceso el 25 de junio de 2007.

3. The Alan Guttmacher Institute. Panorama general del aborto clandestino en América Latina. (Sitio en Internet) Disponible en: http://www.guttmacher.org/pubs/1997/01/01/ib12sp.pdf Último Acceso el 2 de junio de 2007.

4. Arie S. Woman dies after doctors fail to intervene because of new abortion law in Nicaragua. BMJ 2006; 18(333):1037.

5. Replogle J. Nicaragua tightens up abortion laws. The Lancet 2007; 369: 15-16.

6. Besio Rollero M. Consideraciones Éticas sobre el Aborto Terapéutico. Boletín de la escuela de medicina. (Sitio en Internet) Disponible en: http://escuela.med.puc.cl/publ/Boletin/Etica/ConsideracionesEticas.html Último Acceso el 2 de junio de 2007.

7. República de Nicaragua. Ley de Derogación al Artículo 165 del Código Penal Vigente. La Gaceta. (Sitio en Internet) Disponible en: http://legislacion.asamblea.gob.ni/Normaweb.nsf/b92aaea87dac762406257265005d21f7/cb461294f 9939e56062572340070aae9? OpenDocument Último Acceso el 2 de junio de 2007.

8. Organización de Estados Americanos. Organización del Derecho Internacional. Tratados Multilaterales. Convención americana Sobre Derechos Humanos. Pacto de San José Costa Rica: 1969 (Sitio en Internet) Disponible en: http//www. oas.org/juridico/spanish/firmas/b-32.html Último Acceso el 25 de junio de 2007.

9. Base de Datos Políticos de las Américas. Constitución de Nicaragua de 1987, con Reformas de 1995. (Sitio en Internet) Disponible en: www.oas.org/juridico/MLA/sp/nic/sp_nic-int-text-const.pdf Último Acceso el 25 de junio de 2007-

10. Lolas F. Bioética: el diálogo moral en las ciencias de la vida. Santiago de Chile: Mediterráneo; 2003.

Recibido: 24 de agosto de 2007

Aceptado: 29 de septiembre de 2007 